\title{
SISTEM FUZZY INFERENSI UNTUK CUSTOMISE FAN PADA SISTEM RUMAH CERDAS
}

\author{
Andi Farmadi1), Dwi Kartini 2), Muliadi ${ }^{3)}$, \\ 1),2),3) Ilmu komputer Universitas Lambung Mangkurat \\ Jl.Ahmad Yani Km36, Banjarbaru \\ andifarmadi@gmail.com
}

\begin{abstract}
Smart machine-based home development is becoming the current trend because the system can be controlled intelligently by machines. The air conditioning system without the use of air conditioning requires a type of fan to stabilize the temperature and humidity outside the house and inside the house using a blower fan or also called an exhaust fan, but this fan is only limited to circulating air circulation between the outside air and inside the house so that the tendency for the inside air adjust to the outside air, to control the air according to the user it will be manually customized by the user. And for fans in the home room a fan is used which blows air around the fan in circulation. The application of the fuzzy system can provide a fan rotation system that is done intelligently by the machine, which can adjust the balance between the outside air and indoor air to reach air confort or cool. Fuzzy system is applied using Sugeno fuzzy inference using 81 rules to customize the exhaust fan and fan in the room.
\end{abstract}

Keywords: Fuzzy system, Smart home, Sugeno fuzzy..

\begin{abstract}
Abstrak
Pengembangan pada rumah berbasis mesin cerdas menjadi trend saat ini karena sistem tersebut dapat dikendalikan secara cerdas oleh mesin. Sistem pendingin ruangan yang tanpa menggunakan AC diperlukan jenis kipas untuk menstabilkan suhu dan kelembaban di luar rumah dan di dalam rumah menggunakan kipas blower atau disebut juga exhaust fan, namun kipas ini hanya sebatas mengalirkan udara secara sirkulasi antara udara luar dan dalam rumah sehingga kecenderungannya udara dalam menyesuaikan dengan udara luar ruangan, untuk mengontrol udara sesuai dengan user maka akan dilakukan customise secara manual oleh pengguna. Dan untuk kipas dalam ruangan rumah digunakan kipas yang menghembuskan udara sekitar kipas secara sirkulasi. Penerapan Sistem fuzzy dapat memberikan sistem customise putaran kipas yang dilakukan secara cerdas oleh mesin, yang dapat menenyesuaikan keseimbangan antara udara luar dan udara dalam ruangan mencapai udara confort atau sejuk. Sistem fuzzy yang diterapkan menggunakan fuzzy inferensi sugeno dengan menggunakan 81 rule untuk mencustomise keadaan exhaust fan dan kipas angin di dalam ruangan.
\end{abstract}

Kata kunci : Sistem Fuzzy, Rumah Cerdas, Fuzzy Sugeno. 


\section{PENDAHULUAN}

Smart home adalah rumah dengan manajemen kontrol dilakukan oleh mesin cerdas menggunakan aplikasi Artifical Intelegency, pengembangan pada rumah berbasis mesin cerdas menjadi trend saat ini karena sistem tersebut dapat dikendalikan secara cerdas oleh mesin, manusia sebagai pemakai sistem hanya akan memantau jalannya sistem. Salah satu pengontrolan pada rumah cerdas adalah pengontrolan menggunakan kipas internal rumah dan kipas pembuang/pengisap udara atau sering disebut juga blower, kipas ini dipilih karena lebih irit penggunaan daya listrik dan dengan harga yang relatif lebih murah dibandingkan mengunakan $\mathrm{AC}$, juga ramah lingkungan, karena tidak menggunakan gas apapun pada prosesnya, yang hanya menghembuskan angin untuk menyegarkan udara sekitar kipas tersebut, yang sering menjadi kendala adalah pemanfaatan kipas angin yang masih sering dianggap ribet, karena pengontrolan kecepatan putar yang masih dilakukan secara manual, begitupula pada penggunaan kipas blower rumah, yang menyeimbangkan udara pada lingkungan ekternal dan internal rumah, sehingga suhu dan kelembaban eksternal dan internal rumah dibuat sedemikian hingga menjadi cenderung sama, namun kesesuaian suhu luar dan dalam rumah tidak selamanya membuat nyaman atau segar bagi pengguna sistem, atau orang yang berada di dalam rumah. Kipas blower akan menjadi lebih efektif bila suhu internal ruangan disesuaikan pada fungsi wilayah daerah nyaman atau bisa kita kontrol kapan blower kita nyalakan dan kapan kita hentikan nyalanya secara tepat.

Pengontrolan yang dibuat secara otomatis yang menyesuaikan pada fungsi kenyamanan membuat pengguna sistem di dalam ruangan menjadi lebih nyaman, namun akan menjadi banyak cutomisasi kipas dan sekaligus blower yang dilakukan untuk mencapai kondisi keadaan confort (kenyamanan/segar) atau mendekati keadaan tersebut pada internal rumah. Salah satu solusi yang bisa di lakukan yaitu mejadikan mesin kontrol sistem menjadi cerdas dengan menlakukan injeksi sistem cerdas artificial intelegensia menggunakan fuzzy inferensi sistem. Sistem fuzzy yang sering digunakan pada mesin adalah mengunakan fuzzy inferensi sugeno.

\section{METODOLOGI PENELITIAN}

Kipas Exhaust untuk menurunkan atau menaikkan kelembaban dan suhu dalam ruangan kemudian kipas angin digunakan untuk menaikkan kondisi confort (sejuk) dalam ruangan, sistem akan dibuat dengan menjalankan exhaus fan terlebih dahulu sampai kondisi udara lingkungan dalam ruangan menjadi sejuk atau mendekati sejuk, kemudian jika kondisi telah mendekati atau telah mencapai keadaan tersebut maka exhaus fan akan di matikan dan mesin akan menjalankan kipas angin dengan customisasi secara otomatis.

Penentuan variabel input yang mejadi dasar dalam menentukan kondisi exhaust fan dan kipas angin. Variabel input terdiri empat variabel yaitu suhu dalam ruangan (TD), suhu luar ruangan (TL), kelembaban dalam ruangan (KD) dan kelembaban luar ruangan (KL), variabel output terdiri 2 variabel yaitu variabel kecepatan kipas exhaust (EF) dan variabel Kipas Angin (KA). Variabel input suhu 
dalam dan suhu luar ruangan dibuat dalam tiga kategori himpunan yaitu dingin, sedang dan panas dengan range kerja 0o C - 50o C, sedangkan variabel kelembaban dalam dan kelembaban luar ruangan dibuat dalam 3 kategori himpunan yaitu basah, sedang dan kering pada range kerja $30 \%-70 \%$. Untuk variabel output exhaust fan dibuat dalam 3 kondisi himpunan yaitu off (0), lambat (1) dan cepat (2), variabel output kipas angin dibuat dalam 4 kondisi himpunan yaitu off (0), lambat (1), sedang (2), cepat (3). Rule base dijadikan dasar untuk cutomisasi kipas, ada 81 rule customisasi yang dibuat untuk otomatisasi kipas.

Pemrosesan inferensi menggunakan sistem inferensi sugeno untuk mencapai kondisi akhir kipas.

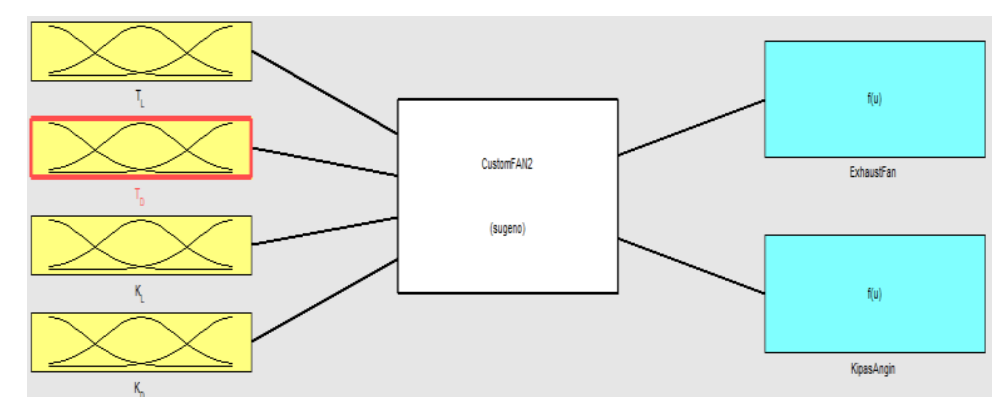

Gambar 1. Sistem inferensi menggunakan fuzzy segeno.

\section{HASIL DAN PEMBAHASAN}

\subsection{Variabel input Suhu Luar $\left(T_{L}\right)$}

variabel input1 adalah Suhu luar ruangan $\left(\mathrm{T}_{\mathrm{L}}\right)$ menggunakan 3 himpunan fuzzy (fuzzy set) dengan grafik trapesium pada pembentukan masing-masing himpunan pada range $0^{\circ} \mathrm{C}-50^{\circ} \mathrm{C}$.

Tabel1. Fuzzy Set Input suhu Luar ruangan

\begin{tabular}{|c|c|c|}
\hline Fuzzy set & Grafik & Range \\
\hline Dingin & trapmf & {$\left[\begin{array}{llll}0 & 0 & 10 & 20\end{array}\right]$} \\
\hline Sedang & trapmf & {$\left[\begin{array}{llll}10 & 20 & 30 & 40\end{array}\right]$} \\
\hline Panas & trapmf & {$\left[\begin{array}{lllll}30 & 40 & 50 & 50\end{array}\right]$} \\
\hline
\end{tabular}

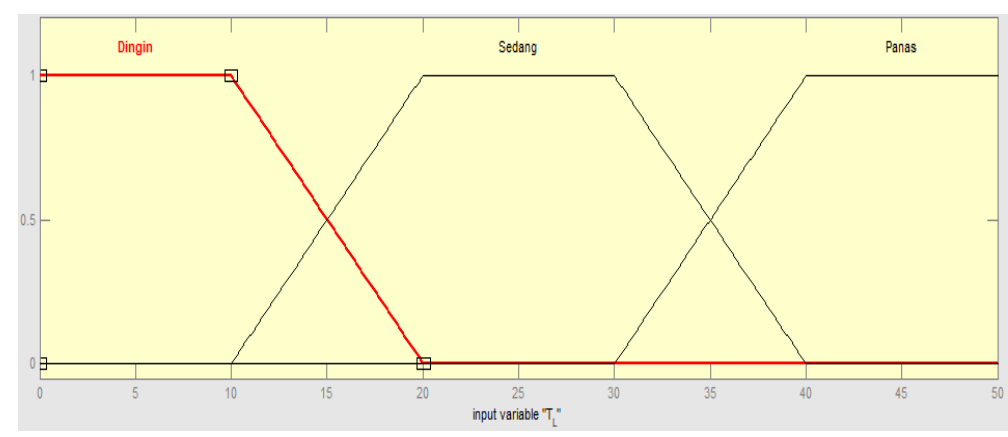

Grafik 2. Grafik Fungsi Keanggotaan Suhu Luar Ruangan 


\subsection{Variabel Input Suhu Dalam $\left(T_{D}\right)$}

variabel input2 adalah Suhu luar ruangan ( $\left.\mathrm{T}_{\mathrm{D}}\right)$ menggunakan 3 himpunan fuzzy (fuzzy set) dengan grafik trapesium dan segitiga pada pembentukan masingmasing himpunan pada range $0^{\circ} \mathrm{C}-40^{\circ} \mathrm{C}$..

Tabel 2. Fuzzy set input suhu dalam ruangan

\begin{tabular}{|c|c|c|}
\hline Fuzzy set & Grafik & Range \\
\hline Dingin & Trapmf & {$\left[\begin{array}{llll}0 & 0 & 10 & 10\end{array}\right]$} \\
\hline Sedang & Trimf & {$\left[\begin{array}{lll}10 & 20 & 30\end{array}\right]$} \\
\hline Panas & Trapmf & {$\left[\begin{array}{lllll}20 & 30 & 40 & 40\end{array}\right]$} \\
\hline
\end{tabular}

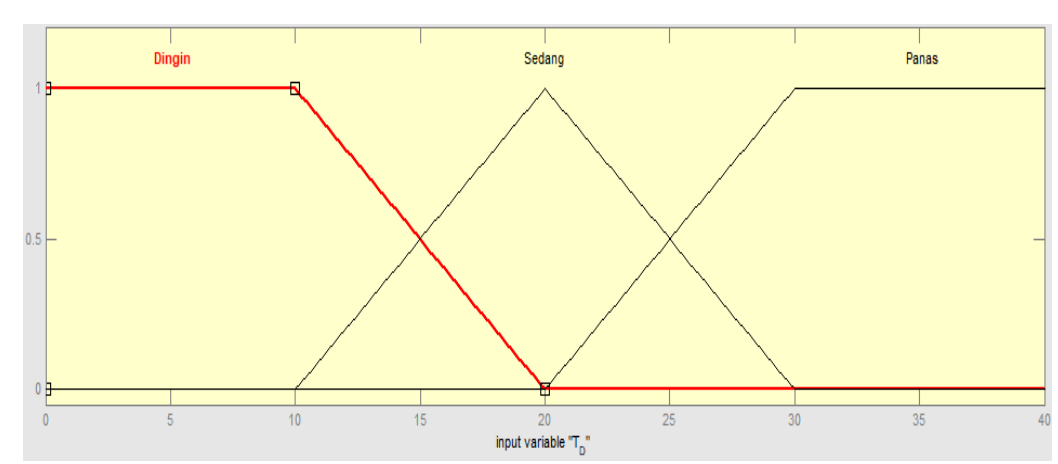

Gambar 3. Grafik Fungsi Keanggotaan Suhu Dalam Ruangan

\subsection{Variabel Input Kelembaban Luar Ruangan $\left(\mathrm{K}_{\mathrm{L}}\right)$}

variabel input 3 adalah Kelembaban luar ruangan $\left(\mathrm{K}_{\mathrm{L}}\right)$ menggunakan 3 himpunan fuzzy (fuzzy set) dengan grafik trapesium pada pembentukan masingmasing himpunan.

Tabel 3. Fuzzy set input kelembaban luar ruangan

\begin{tabular}{|c|c|c|}
\hline Fuzzy set & Grafik & Range \\
\hline Kering & Trapmf & {$\left[\begin{array}{llllll}30 & 30 & 35 & 45\end{array}\right]$} \\
\hline Sedang & Trapmf & {$\left[\begin{array}{llll}35 & 45 & 55 & 65\end{array}\right]$} \\
\hline Basah & trapmf & {$\left[\begin{array}{llll}55 & 65 & 70 & 70\end{array}\right]$} \\
\hline
\end{tabular}

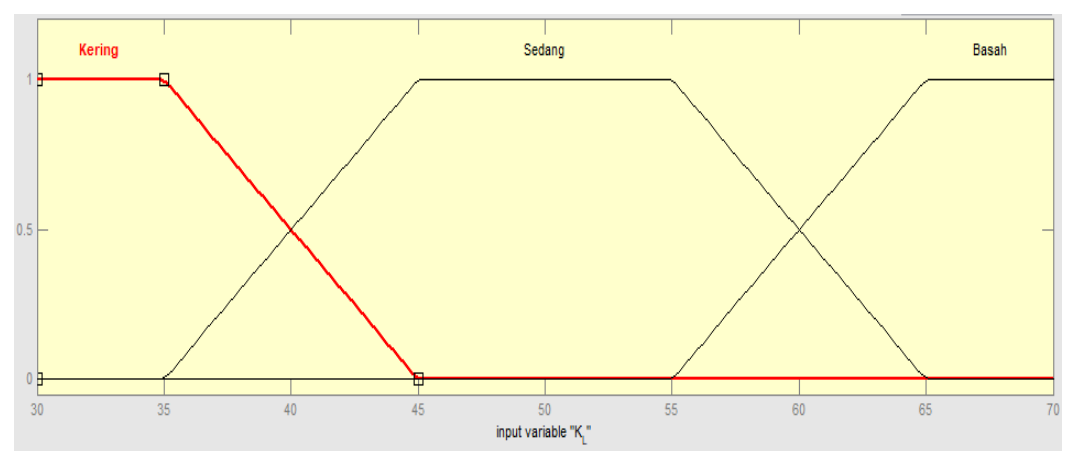

Gambar 4. Grafik Fungsi Keanggotaan Kelembaban Luar Ruangan 


\subsection{Variabel Input Kelembaban Dalam Ruangan (KD)}

variabel input 3 adalah Kelembaban luar ruangan $\left(\mathrm{K}_{\mathrm{L}}\right)$ menggunakan 3 himpunan fuzzy (fuzzy set) dengan grafik trapesium dan triangular pada pembentukan masing-masing himpunan, range kerja pada $30 \%-70 \%$.

Tabel 4. Fuzzy set kelembaban dalam ruangan

\begin{tabular}{lll}
\hline Fuzzy set & Grafik & Range \\
\hline Kering & Trapmf & {$[30304050]$} \\
Sedang & Trimf & {$[405060]$} \\
Basah & trapmf & {$[50607070]$} \\
\hline
\end{tabular}

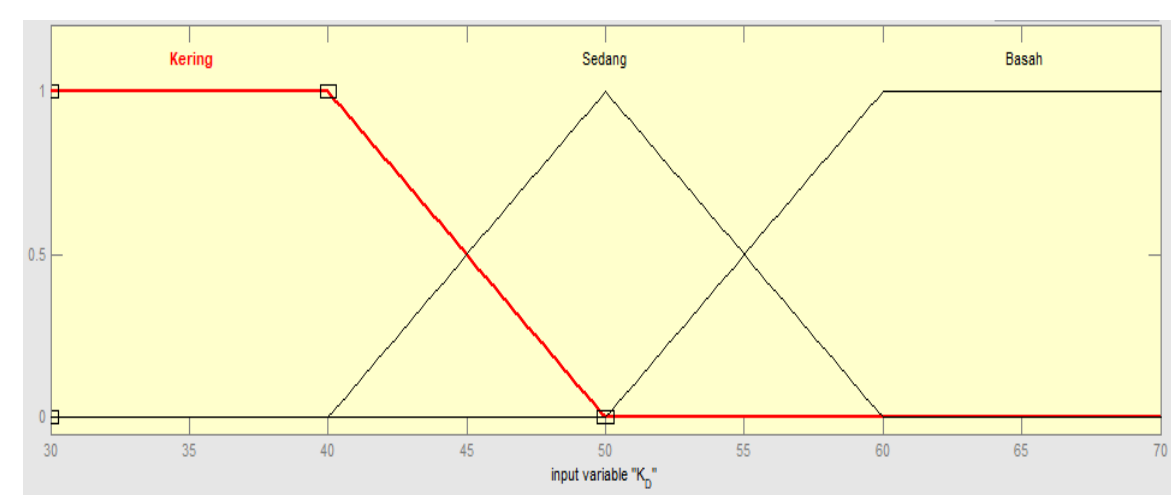

Gambar 5. Grafik Fungsi Keanggotaan Kelembaban Dalam Ruangan

\subsection{Variabel Output Exhaust Fan}

variabel Output 1 adalah Exhaust Fan menggunakan 3 himpunan fuzzy (fuzzy set) dengan grafik konstan pada pembentukan masing-masing himpunan dengan nilai masing-masing off (0), lambat(1) dan cepat(2).

Tabel 5. Fuzzy set Exhaust Fan

\begin{tabular}{llc}
\hline Fuzzy set & Grafik & Value \\
\hline Off & Constant & {$[0]$} \\
Lambat & Constant & {$[1]$} \\
Cepat & Constant & {$[2]$} \\
\hline
\end{tabular}

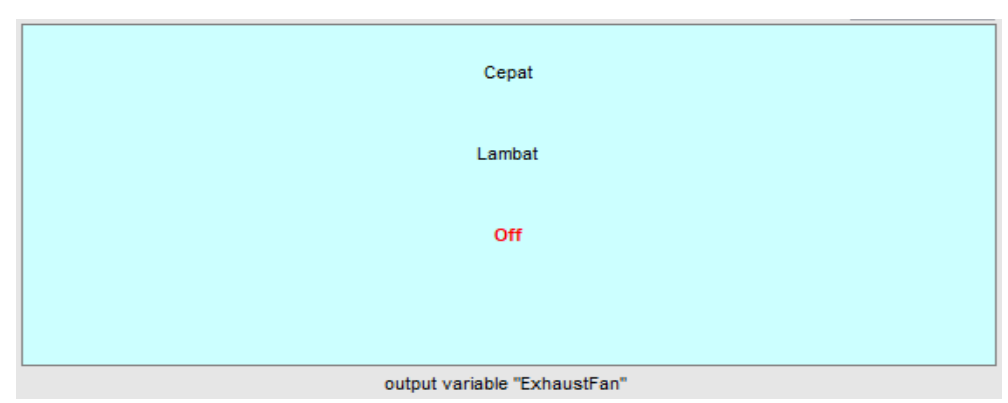

Gambar 6. Grafik Fungsi Keanggotaan Kipas Exchaus 


\subsection{Variabel Output Kecepatan Kipas Angin}

variabel Output 1 adalah Exhaust Fan menggunakan 4 himpunan fuzzy (fuzzy set) dengan grafik konstan pada pembentukan masing-masing himpunan dengan nilai masing-masing off (0), lambat(1), Sedang (2) dan cepat(3).

Tabel 6. Fuzzy set Exhaust Fan

\begin{tabular}{lcc}
\hline Fuzzy set & Grafik & Value \\
\hline Off & Constant & {$[0]$} \\
Lambat & Constant & {$[1]$} \\
Sedang & Constant & {$[2]$} \\
Cepat & Constant & {$[3]$} \\
\hline
\end{tabular}

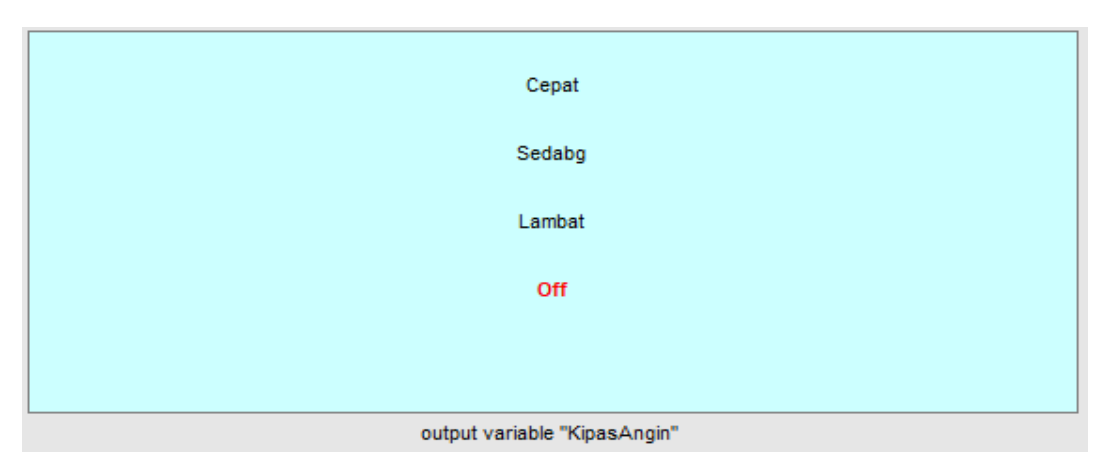

Gambar 7. Grafik Fungsi Keanggotaan Kecepatan Kipas

\subsection{Rule base}

Pembentukan Rule Base untuk menentukan customisasi dari masingmasing output yaitu exhaus fan dan kipas angin, dengan terdapat 81 rule customisasi

Tabel 7. Rule Base customisasi Exhaust Fan dan Kipas Angin

\begin{tabular}{|c|c|c|c|c|c|c|}
\hline \multirow{2}{*}{$\begin{array}{l}\text { Nama } \\
\text { Rule }\end{array}$} & \multicolumn{4}{|c|}{ INPUT } & \multicolumn{2}{|c|}{ OUTPUT } \\
\hline & T_L & K_L & T_D & K_D & Exhaus & Kipas \\
\hline Custom 1 & Dingin & Kering & Dingin & Kering & Off & Off \\
\hline Custom 2 & Normal & Kering & Dingin & Kering & Cepat & Lambat \\
\hline Custom 3 & Panas & Kering & Dingin & Kering & Lambat & Lambat \\
\hline Custom 4 & Dingin & Lembab & Dingin & Kering & Lambat & Off \\
\hline Custom 5 & Normal & Lembab & Dingin & Kering & Cepat & Lambat \\
\hline Custom 6 & Panas & Lembab & Dingin & Kering & Lambat & Cepat \\
\hline Custom 7 & Dingin & Basah & Dingin & Kering & Lambat & Off \\
\hline Custom 8 & Normal & Basah & Dingin & Kering & Cepat & Lambat \\
\hline Custom 9 & Panas & Basah & Dingin & Kering & Lambat & Lambat \\
\hline Custom 10 & Dingin & Kering & Normal & Kering & Off & Off \\
\hline$\cdots$ & $\ldots$ & $\cdots$ & $\ldots$ & $\cdots$ & ... & ... \\
\hline Custom 80 & Normal & Basah & Panas & Basah & Cepat & Off \\
\hline Custom 81 & Panas & Basah & Panas & Basah & Off & Cepat \\
\hline
\end{tabular}




\subsection{Kasus}

Sebagai contoh kasus di ambil nilai Suhu Luar $=25^{\circ} \mathrm{C}$, Suhu Dalam $=20^{\circ} \mathrm{C}$, Kelembaban Luar $=50 \%$ dan Kelembaban Luar $=50 \%$, hasil output yang diperoleh dari exhasut Fan = off (0) dan Kipas Angin = lambat $(0,5)$, secara detail grafik fuzzy pada rule, hubngan keadaan udara dalam dan luar terhadapa exhaust fan dan kipas angin dapat dilihat pada gambar di bawah.

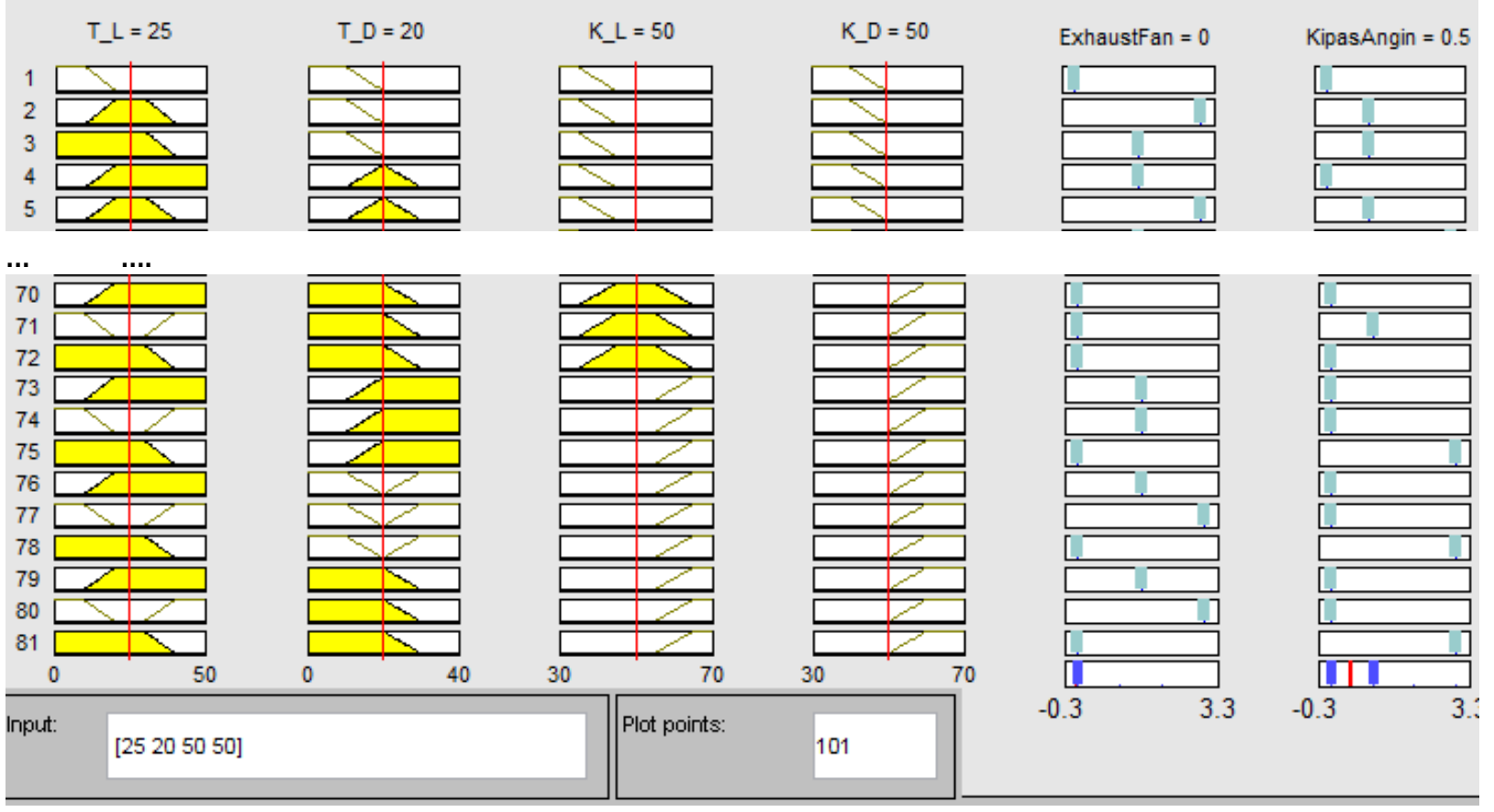

Gambar 8. Grafik Fuzzyfikasi Rule-base Sugeno

Dari hasil hubungan antara suhu luar dan suhu dalam ruangan terhadap kecepatan exhaus fan dapat dilihat dari gambar grafik di bawah ini.

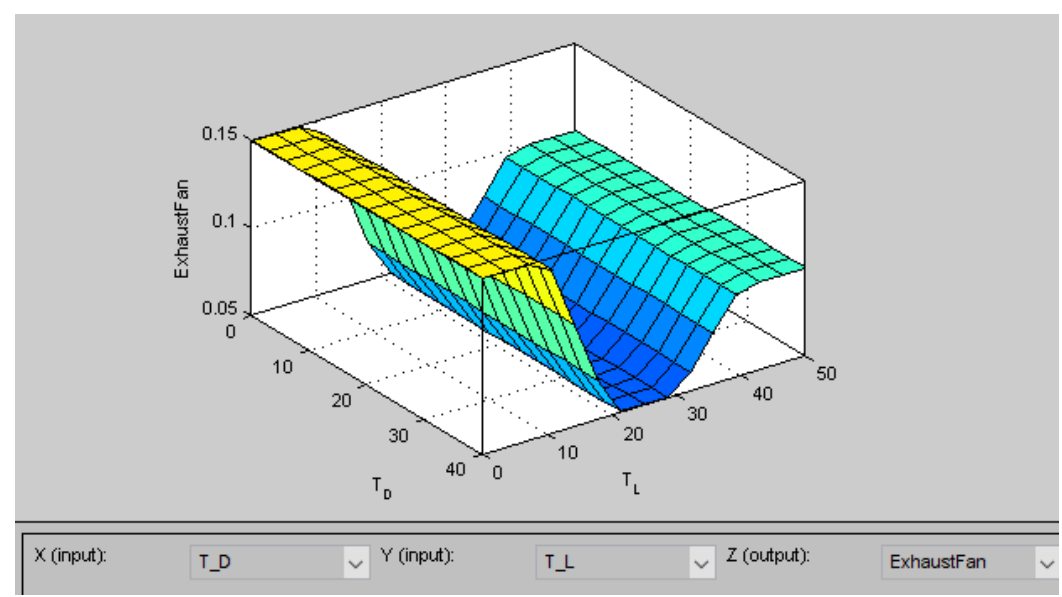

Gambar 9. Grafik hubungan Suhu Dalam ( $\left.\mathrm{T}_{\mathrm{D}}\right)$ dan Suhu Luar $\left(\mathrm{T}_{\mathrm{L}}\right)$ Vs Exhaus Fan 
Dari hasil hubungan antara kelembaban luar dan kelembaban dalam ruangan terhadap kecepatan exhaus fan dapat dilihat dari gambar grafik di bawah ini.

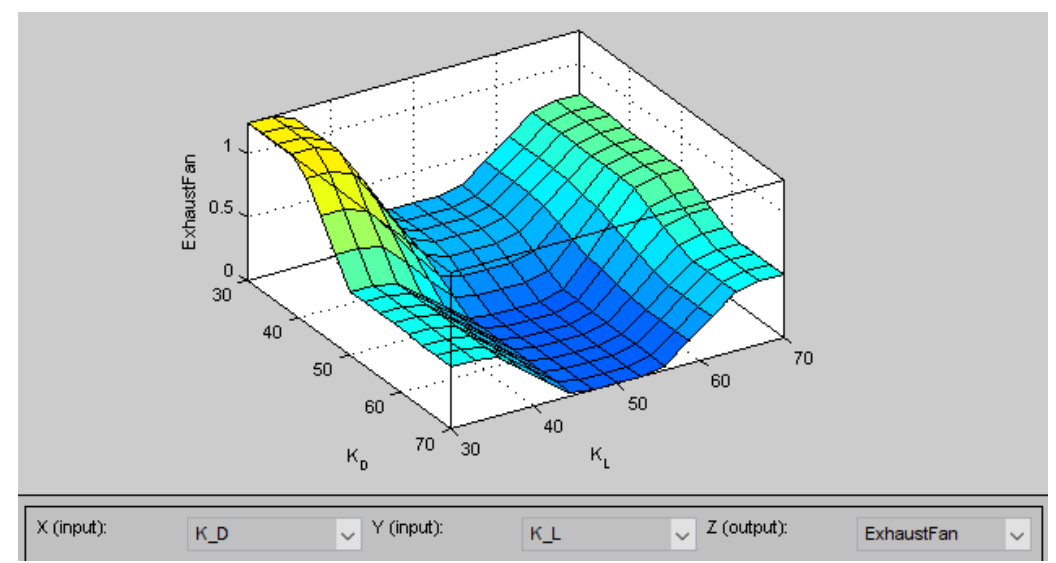

Gambar 10. Grafik Input hubungan Suhu Dalam ( $\mathrm{T}_{\mathrm{D}}$ ) dan Suhu Luar $\left(\mathrm{T}_{\mathrm{L}}\right)$ Vs Exhaus Fan

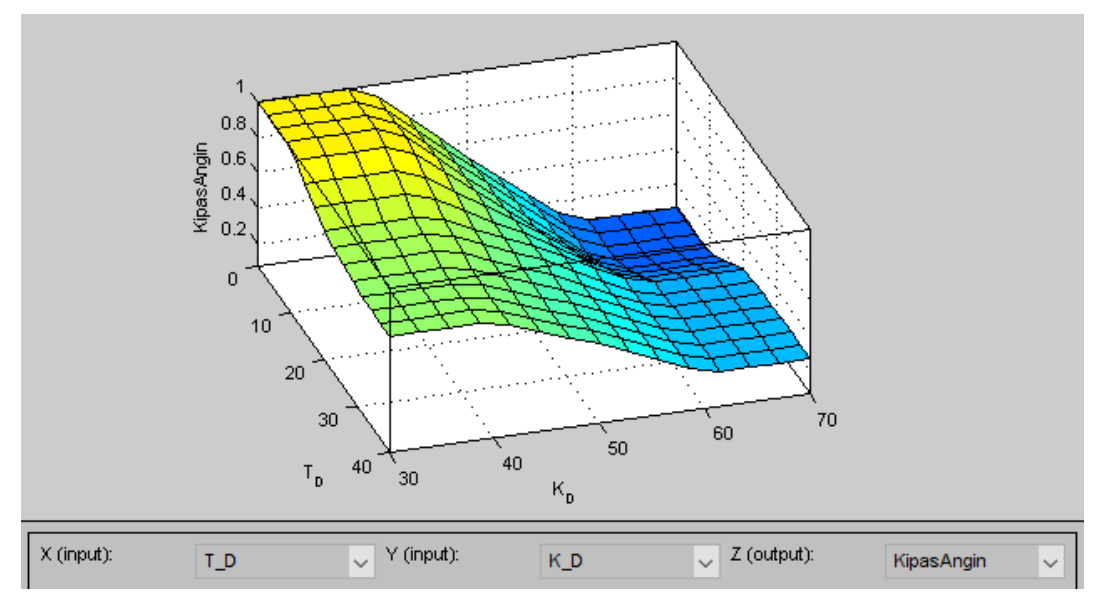

Gambar 11. Grafik Suhu Dalam ( $\mathrm{T}_{\mathrm{D}}$ ) dan Kelembaban Dalam (KD) Vs Kipas Angin

\section{KESIMPULAN}

Dari hasil inferensi fuzzy sugeno di dapatkan bahwa sistem dapat memberikan customisasi keadaan exhaust fan dan kipas angin sebanyak 81 rule secara otomatis. Kecepatan exhaust fan sangat bergantung pada perbedaan udara luar dan dalam ruangan, sedangkan kecepatan kipas angin sangat bergantung pada keadaan udara dalam ruangan hasil dari sirkulasi udara dari exhaus fan. 


\section{DAFTAR PUSTAKA}

[1] Durkin, J. 1994. "Expert Systems Design and Development. New Jersey", Hall International Inc.

[2] Farmadi, 2017, Implementasi Internet of Things ( IoT) pada Sistem Monitoring Rumah Kaca dengan menggunakan Mikrokontroler yang tertanam Sitem Fuzzy, Prosiding Soliter Vol 1, Oktober 2017

[3] Farmadi, Dodon. 2017. "Sistem Fuzzy Logic Tertanam pada Mikrokontroler untuk Penyiraman Tanaman pada Rumah Kaca", Volume 04, No.02 September 2017

[4] Farmadi, Ichsan, 2018. “Implementasi Fuzzy Sugeno Untuk Menentukan Kesesuaian Tanaman Kelapa Sawit Pada Lahan Gambut", Jurnal Klik-Volume 05, No.02 September 2018

[5] Farmadi, Sirajuddin. 2018 Penerapan metode Naive Bayes pada penentuan kualitas air pemijahan Ikan, Jurnal Jentik 2018.

[6] Kusumadewi, Sri. 2003. Artificial Intelligence (Teknik dan Aplikasinya). Graha Ilmu, Yogyakarta 